Title: Intermittently scanned continuous glucose monitoring is associated with high satisfaction but increased $\mathrm{HbA1c}$ and weight in well-controlled youth with

\title{
type 1 diabetes
}

Running title: high acceptance, worse HbA1c in youth on isCGM

Sara Charleer ${ }^{1,2}$, Pieter Gillard ${ }^{1,2}$, Eva Vandoorne ${ }^{3}$, Kelly Cammaerts ${ }^{3}$, Chantal Mathieu ${ }^{1,2}$, Kristina Casteels $s^{3,4}$

${ }^{1}$ Endocrinology, University Hospitals Leuven, Leuven, Belgium

${ }^{2}$ Clinical and Experimental Endocrinology, KU Leuven, Leuven, Belgium

${ }^{3}$ Pediatrics, University Hospitals Leuven, Leuven, Belgium

${ }^{4}$ Development and Regeneration, KU Leuven, Leuven, Belgium

Correspondence author: Kristina Casteels, UZ Leuven, Herestraat 49, 3000 Leuven, Belgium. Phone: +32 163438 11, email: kristina.casteels@uzleuven.be

Acknowledgments: Parts of the study will be presented at the $56^{\text {th }}$ European Association of in September 2020. The authors thank the diabetes nurses of the department of Pediatrics for administering the questionnaires to the participants.

Author contributions: S.C. designed the study, collected and analyzed the data, performed statistical analyses, wrote the manuscript, and made figures and tables. P.G., C.M., and K.Cas. designed the study, discussed the data and wrote the manuscript. E.V. and K.Cam. collected and discussed the data. All authors have read and approved the final manuscript.

Funding: S.C. received a doctoral grant for strategic basic research and P.G. holds a PhD fellowship from Fonds Wetenschappelijk Onderzoek. No industry funding was available for this study.

Conflict of interest: S.C. received travel grants from Medtronic and Roche, unrelated to the present work. P.G. serves or has served on the advisory panel for Novo Nordisk, Sanofi, Boehringer Ingelheim, Janssen Pharmaceuticals, Roche, Medtronic, and Bayer, and financial compensation for these activities has been received by KU Leuven. P.G. serves or has served on the speakers bureau for Merck Sharp \& Dohme, Boehringer Ingelheim, Bayer, Medtronic, Abbott Laboratories, and Roche, and financial compensation for these activities has been received by KU Leuven. KU Leuven received nonfinancial support for P.G. for travel from Sanofi, A. Menarini Diagnostics, Medtronic, and Roche. E.V. and K.Cam. have nothing to disclose. C.M. serves or has served on the advisory panel for Novo Nordisk, Sanofi- 
Aventis, Merck Sharp and Dohme, Eli Lilly, Novartis, AstraZeneca, Boehringer-Ingelheim, Hanmi Pharmaceuticals, Roche, Medtronic, ActoBio Therapeutics, Pfizer, Dianax, and Union Chimique Belge. Financial compensation for these activities has been received by KU Leuven; KU Leuven has received research support for C.M. from Medtronic, Novo Nordisk, Sanofi-Aventis, Merck Sharp and Dohme, Eli Lilly, Roche, Abbott, ActoBio Therapeutics, and Novartis; C.M. serves or has served on the speakers bureau for Novo Nordisk, Sanofi-Aventis, Merck Sharp and Dohme, Eli Lilly, Boehringer-Ingelheim, AstraZeneca, and Novartis. Financial compensation for these activities has been received by KU Leuven K.Cas. serves or has served on the advisory panel for Novo Nordisk. KU Leuven received nonfinancial support for K.Cas. for travel from Abbott, Medtronic, and Sandoz. 


\section{ABSTRACT}

Objective: We undertook a 24-month prospective observational single-center real-world trial to study impact of access to intermittently scanned continuous glucose monitoring (isCGM) on quality of life (QOL) and glycemic control of youth with type 1 diabetes (T1D).

Methods: Between September 2016 and November 2017, 138 children and adolescents with T1D were recruited. Demographic, metabolic, and QOL data were collected during 24 months of routine followup. Primary endpoint was evolution of $\mathrm{QOL}$, with secondary outcomes change in $\mathrm{HbA1c}$, occurrence of acute diabetes complications, and school absenteeism.

Results: Ninety-two percent of participants found isCGM more user-friendly than capillary finger-stick tests and had high treatment satisfaction, without change in diabetes-specific QOL. HbA1c significantly increased from 7.2\% (7.0-7.3) (55 mmol/mol [53-56]) at baseline to $7.6 \%(7.4-7.8)(60 \mathrm{mmol} / \mathrm{mol}$ [5762]) at 12 months $(P<0.0001)$ and was unchanged up to 24 months. Overall increase was mainly driven by children with baseline $\mathrm{HbA} 1 \mathrm{c}<7.0 \%$ ( $<53 \mathrm{mmol} / \mathrm{mol})$. Additionally, BMl adjusted for age was higher at study end. In year before isCGM, 228 days per 100 patient-years of school absenteeism were reported, which dramatically decreased to 13 days per 100 patient-years $(P=0.016)$ after 24 months. Parents of children also reported less work absenteeism $(P=0.011)$.

Conclusion: Use of isCGM by T1D pediatrics is associated with high treatment satisfaction and less days of school absence. However, increased $\mathrm{HbA1c}$ and weight may reflect a looser lifestyle, with less attention to diet and more avoidance of hypoglycemia. Intensive education specifically focusing on these points may mitigate these issues.

Keywords: type 1 diabetes mellitus, children, intermittently scanned continuous glucose monitoring, quality of life, absenteeism 


\section{INTRODUCTION}

Management of type 1 diabetes (T1D) is a task performed around the clock that can form a challenge for children, adolescents, and their parents, often characterized by a worsening in glycemic control during adolescence. ${ }^{1,2}$ Suboptimal diabetes control early in life is a risk factor for developing microvascular and macrovascular complications later in life. ${ }^{3}$ In addition, the negative impact of struggling with diabetes management on mental well-being and quality of daily living should not be put aside as this can lead to depression or even suicide. ${ }^{4,5}$ The use of diabetes technology has the hope of lessening the burden of diabetes management and improve outcomes in youth. Since the introduction of continuous glucose monitoring (CGM), self-management of type 1 diabetes (T1D) has changed dramatically. The availability to visualize day-to-day trends, hypoglycemic events, time in range, and the generation of an informative one page ambulatory glucose profile can enhance individualized diabetes care and day-to-day changes in insulin therapy. ${ }^{6}$ CGM has been recognized as a benefit in the adult population with favorable results on hypoglycemia risk, quality of life, and hospitalization rate..$^{7-10}$ However, results in the pediatric age group are less certain. ${ }^{8,11,12}$

From 2014 onwards, intermittently scanned CGM (isCGM) (Freestyle Libre, Abbott Diabetes Care, Witney, UK) was introduced, and has been approved for use in children older than 4 years of age in January 2016. This device differs from CGM by the need for active "scanning" of the sensor, absence of alarms for hypo- and hyperglycemia in the first version, no need for calibration, and a sensor lifespan of 14 days. ${ }^{13}$ To date, only few studies report isCGM use of longer than 6 months with a follow-up of maximum 12 months. ${ }^{14-16}$ These observational studies show mixed results for glycemic outcomes, and quality of life was not always part of the assessment. ${ }^{14}$ Additionally, the effect on diabetes-related absence days from school has not been studied before. Thus, it remains unclear whether the long-term use of isCGM has a benefit in an unselected population in real-world settings.

Therefore we wanted to provide an answer to the question whether 24-month use of isCGM in an unselected real-world cohort of youth living with T1D had an impact on quality of life, diabetes control, acute complication risk, and absence from school.

\section{METHODS}

\section{Study design and participants}

Youth with T1D were consecutively recruited between September 2016 and November 2017 for this single-center prospective observational real-world cohort study (FUTURE trial, Flash glucose monitoring study for diabetes, ClinicalTrials.gov: NCT02898714). Recruitment took place at University 
Hospitals Leuven. All children and adolescents who were planned to start isCGM were proposed to participate and included in the study after signed informed consent of at least one of the parents and informed assent of the person with T1D. The decision to use isCGM was made prior to and independently of their entrance to the study, and was based on preferences of the patients and their parents. Beforehand, we estimated that about 70\% of youth with T1D ( $n=190 / 272$ ) would be willing to use isCGM. For the current analysis, only data from people who were diagnosed with T1D more than three months before start of isCGM were used.

Data were collected during routine clinical follow-up and from validated questionnaires that were presented to the participants at defined time points.

\section{Outcomes}

Primary outcome was defined as evolution over time of quality of life between baseline and 24 months after start of isCGM. Secondary outcomes were change in acute diabetes complications (hypoglycemia and/or ketoacidosis), school absenteeism, work absenteeism of parents, HbA1c, proportion of participants with $\mathrm{HbA} 1 \mathrm{c}<7 \%,<7.5 \%$, and $<8.5 \%$ ( $<53 \mathrm{mmol} / \mathrm{mol},<58 \mathrm{mmol} / \mathrm{mol}, 69 \mathrm{mmol} / \mathrm{mol})$, total daily insulin dose, $\mathrm{BMI}$, reasons to discontinue isCGM, and monitoring complaints.

\section{Device and diabetes management}

In Belgium, people with T1D treated for their diabetes in specialist centers by multidisciplinary teams lead by endocrinologists are free to choose which reimbursed device they use for diabetes management. On August 1, 2016, the first version of the FreeStyle Libre flash glucose monitoring system (Abbott Diabetes Care, Witney, UK) became fully reimbursed for youth with T1D in Belgium. If they chose to switch to isCGM, they were trained individually or in group during two to three hours by experienced diabetes educator nurses as part of the standard of care.

Children and their parents were trained in setting up the device, inserting the sensor on the back of the upper arm, scanning the sensor with the reader, interpreting trend arrows and glucose sensor reports, uploading glucose sensor data using the designated diabetes management software, entering extra information in the reader (e.g. carbohydrate intake, insulin dosing, exercise), and understanding when a confirmatory capillary glucose test was recommended.

After the training session, the device was immediately unblinded. They received instructions to scan frequently (at least four times daily), to adapt insulin dose on the basis of the actual value, and to take associated trend arrows into account. During every routine diabetes consultation, isCGM data were uploaded and relevant reports were generated using the designated software. These reports were thoroughly reviewed together with the multidisciplinary team and, if necessary, treatment adaptations were proposed. 


\section{Data Collection}

Pre-specified clinical data were collected from the electronic medical records from 12 months before until 24 months after start of isCGM. BMI was converted to standard deviation scores (SDS). ${ }^{17}$

For the primary outcome, different questionnaires were presented to participants at baseline, 6,12 , and 24 months. All questionnaires (Diabetes Quality of Life for Youth [DQOLY] ${ }^{18}$ and Hypoglycemia Fear Survey [HFS] for children ${ }^{19}$ ) were validated in both Belgian languages (Dutch and French) and in English, and presented to participants and their parents in their mother tongue or the language they understood best. After 6,12 , and 24 months, participants were asked how satisfied they were with the new device on a 10-point Likert-scale ranging from 0 ("not at all satisfied") to 10 ("very satisfied, could not be better"), and they could indicate if they found isCGM less convenient, similar, or more convenient than finger-stick testing. Additionally, comments on the use of isCGM were gathered and grouped for qualitative research purposes.

At baseline, after 6,12 , and 24 months, children/parents were asked to report on how many diabetesrelated events the children experienced, how many days the children missed school due to their diabetes, and how many days their parents were absent from work due to the diabetes of their child, all in the previous 6 months prior to the routine clinic visits (Supplementary Table 1). Patient-reported medical interventions, emergency room admissions, and hospitalizations for (symptoms of) acute diabetes complications (hypoglycemia/ketoacidosis/ketosis) were validated using hospital records. Hospitalizations for ketoacidosis at diagnosis of type 1 diabetes were excluded.

Reports of isCGM data were generated using the designated diabetes management software (FreeStyle Libre software version 1.0 and LibreView) and used to determine scan frequency.

\section{Ethics}

The protocol was approved by the coordinating institutional review board (Ethics Committee University Hospitals Leuven). The study was executed in line with Good Clinical Practice guidelines of the Declaration of Helsinki in its latest form.

\section{Statistical analysis}

Post-hoc, the total population was grouped based on clinically relevant parameters for subgroup analyses: quantiles of mean scan frequency over the 24-month follow-up period ( $<9$ times per day and $\geq 9$ times per day), two age-groups ( $\leq 12$ years and $>12$ years), and clinically relevant subgroups of baseline $\mathrm{HbA} 1 \mathrm{c}(<7.0 \%$ and $\geq 7.0 \%,<7.5 \%$ and $\geq 7.5 \%$, and $<8.5 \%$ and $\geq 8.5 \%$ [ $<53$ and $\geq 53 \mathrm{mmol} / \mathrm{mol}$, $<58$ and $\geq 58 \mathrm{mmol} / \mathrm{mol},<69$ and $\geq 69 \mathrm{mmol} / \mathrm{mol}])$. The number of people in different subgroups at the different time points is shown in Supplementary Table 2. 
We used a linear mixed model to evaluate DQOLY (satisfaction, impact, and worry subscales), HFS (behavior and worry subscales), $\mathrm{HbA1c}$, insulin dose per day, and BMI with an unstructured covariance matrix for four repeated measurements within the same patient. By using a linear mixed model, cases with missing data still contributed to the analyses (see Supplementary Table 3 for number of missing cases per outcome). Differences in $\mathrm{HbA} 1 \mathrm{c}$ between the two scan frequency groups were analyzed using Mann-Whitney U test. Pearson's correlation coefficient was used to analyze the relationship between scan frequency and HbA1c. The McNemar's test was used to evaluate the evolution of proportion of participants (with $\mathrm{HbA} 1 \mathrm{c}<7 \%$ and $<7.5 \%$ [ $<53$ and $<58 \mathrm{mmol} / \mathrm{mol}$ ], with school/work absenteeism, needing help from third parties due to hypoglycemia, having hypoglycemic comas, and with admissions due to hypoglycemia/ketoacidosis).

Differences in days of school/work absenteeism, number of times help from third parties was needed, number of hypoglycemic comas, and number of days of hospitalizations for hypoglycemia/ketoacidosis per 100 patient-years were assessed with the Wilcoxon signed-rank test.

All tests were performed with SPSS software for Windows (IBM SPSS Statistics version 26, Armonk, USA) and conducted at the 0.05 significance level. Data are shown as mean with SD, or least-squares mean with $95 \% \mathrm{Cl}$ for results from the linear mixed model, unless otherwise stated.

\section{RESULTS}

\section{Participants}

A total of 138 children and adolescents with T1D since $>3$ months were included (Table 1). One hundred thirty-four (97\%) and 122 (88\%) participants used isCGM for at least 12 and 24 months, respectively. Of sixteen (11.6\%) children who stopped participating in the study, $9(6.5 \%)$ were lost to follow-up, and 7 (5.1\%) stopped using isCGM (Supplementary Figure 1). Two participants stopped using isCGM because they preferred finger stick tests $(n=2 / 7,28.6 \%)$. Other reasons were mentioned only once: incidence of a severe hypoglycemic event, switch to real-time CGM, allergic reaction on sensor, sensor values were confronting, and the sensor was too visible ( $n=1 / 7,14.3 \%$ for each reason). On average, children scanned 9.3 \pm 5.7 times per day over 24 months.

\section{Quality of life}


The DQOLY satisfaction subscale was significantly improved after 12 months (68.8 [67.4-70.3] at baseline vs 71.2 [69.8-72.7] at 12 months, $P<0.0001)$, but dropped slightly by 24 months (70.2 [68.871.5], $P=0.055$ vs baseline). DQOLY impact and worry, and HFS behavior and worry subscales did not change significantly over 24 months (Table 2). However, there was a trend towards higher HFSbehavior scores and lower HFS-worry scores, which was also present in the subgroup analyses (Table 2 and Supplementary Table 4).

When evaluating quality of life changes based on age, both those $\leq 12$ years and those $>12$ years of age had higher scores for DQOLY satisfaction at 6 months. Those $\leq 12$ years of age could keep the higher scores until 24 months, while youth $>12$ years of age could not. Improvements in DQOLY subscales were maintained for children who scanned $<9$ times per day, while those with a scan frequency of $\geq 9$ times per day only showed an improvement in DQOLY satisfaction at 6 and 12 months when compared to baseline. For the subgroup analysis based on baseline HbA1c, each subgroup had higher DQOLY satisfaction up to 12 months (Supplementary Table 4).

Overall, participants self-reported high satisfaction with the device $(8.2 \pm 1.4,8.3 \pm 1.2$, and $8.0 \pm 1.4$ at 6 , 12 , and 24 months respectively on scale from 0 to 10 ) and they agreed almost unanimously that isCGM was more convenient than finger-stick tests ( $n=93 / 97$ [95.9\%], $n=90 / 92$ [97.8\%], and $n=71 / 77$ [92.2\%] after 6,12 , and 24 months, respectively)

\section{Change in acute diabetes complications and school absenteeism}

The number of participants admitted to emergency room or hospital because of hypoglycemia decreased, although not reaching statistical significance $(p=0.453)$. The same was observed for other acute hypoglycemic events. On the other hand, more hospitalizations due to diabetic ketoacidosis were observed, but this change was also not significant (Table 3).

In the year before use of isCGM, 228 days per 100 patient-years of school absence were reported. After 24 months, this significantly decreased to 13 days per 100 patient-years ( $P=0.016)$. Parents of children also reported less days off work, from 149 days per 100 patient-years before to 18 days per 100 patient-years after 24 months of isCGM use $(P=0.011)$ (Table 3$)$.

\section{Change in HbA1c}

The proportion of children with $\mathrm{HbA} 1 \mathrm{c}<7.5 \%(<58 \mathrm{mmol} / \mathrm{mol})$ was $66.7 \%(\mathrm{n}=92 / 138)$ at baseline and was stable up to 6 months ( $\mathrm{n}=93 / 137,67.9 \% ; P=0.851$ ). Between 6 and 12 months, it significantly decreased to $54.5 \%$ ( $n=73 / 134 ; P=0.003$ vs 6 months, $P=0.006$ vs baseline) and from 12 months onward it remained stable until 24 months ( $n=72 / 122,59.0 \%$ after 24 months; $P=0.701$ vs 12 months, $P=0.019$ vs baseline). 
The same was seen for the proportion of children with $\mathrm{HbA} 1 \mathrm{c}<7.0 \%(<53 \mathrm{mmol} / \mathrm{mol})$, which decreased from $47.8 \%(n=64 / 138)$ at baseline to $27.6 \%(n=37 / 134)$ after 12 months $(P<0.0001)$ and was stable thereafter ( $\mathrm{n}=38 / 122,31.1 \%$ at 24 months; $P=0.851$ vs 12 months, $P=0.001$ vs baseline).

HbA1c significantly increased from baseline to 12 months $(7.2 \%$ [7.0-7.3], $55 \mathrm{mmol} / \mathrm{mol}$ [53-56] at baseline vs 7.6\% [7.4-7.8], $60 \mathrm{mmol} / \mathrm{mol}$ [57-62] at 12 months; $P<0.0001)$ and was sustained until 24 months (7.6\% [7.4-7.8], $60 \mathrm{mmol} / \mathrm{mol}[57-62], P<0.0001$ vs baseline) (Figure 1a).

This overall increase was mainly driven by the group of children with baseline HbA1c $<7.0 \%(<53$ $\mathrm{mmol} / \mathrm{mol})$. Their HbA1c rose from $6.3 \%(6.2-6.4)(45 \mathrm{mmol} / \mathrm{mol}$ [44-46]) to $6.9 \%$ (6.7-7.1) (52 $\mathrm{mmol} / \mathrm{mol}[50-54])$ over 24 months $(P<0.0001)$, whereas those with baseline HbA1c $\geq 7 \%(\geq 53$ $\mathrm{mmol} / \mathrm{mol}$ ) remained stable $(7.9 \%$ [7.7-8.1], $63 \mathrm{mmol} / \mathrm{mol}$ [61-65] vs $8.1 \%$ [7.8-8.4], $65 \mathrm{mmol} / \mathrm{mol}$ [62-68] over 24 months; $P=0.086$ ) (Figure 1b). See Supplementary Figure 2 for evolution of HbA1c for subgroups with baseline $\mathrm{HbA} 1 \mathrm{c}<7.5 \%(<58 \mathrm{mmol} / \mathrm{mol})$ and $<8.5 \%(<69 \mathrm{mmol} / \mathrm{mol})$.

Youth $>12$ years of age had worse diabetes control than children $\leq 12$ years of age. However, they showed the same evolution of HbA1c over 24 months of isCGM use (Figure 1c).

During the first 12 months, children who scanned $<9$ times and who scanned $\geq 9$ times per day showed the same increase in HbA1c. However, between 12 and 24 months, those scanning $\geq 9$ times per day showed a slight decrease (7.5\% [7.2-7.7], $58 \mathrm{mmol} / \mathrm{mol}$ [55-61] at 12 months vs $7.2 \%$ [7.0-7.4], 55 $\mathrm{mmol} / \mathrm{mol}[53-57$ ] at 24 months; $P=0.006$ ), while those who scanned $<9$ times per day remained stable (7.8\% [7.5-8.1], $62 \mathrm{mmol} / \mathrm{mol}$ [58-65] at 12 months vs 7.8\% [7.5-8.2], $62 \mathrm{mmol} / \mathrm{mol}$ [58-66] at 24 months; $P=0.651$ ) (Figure 1d). The difference in $\mathrm{HbA1c}$ between the two groups at 24 months was significantly different $(P=0.005)$, whereas this was not the case at the other follow-up moments.

The mean change in $\mathrm{HbA} 1 \mathrm{c}(0.4 \pm 0.8 \%, 5 \pm 8 \mathrm{mmol} / \mathrm{mol})$ was not correlated with mean scan frequency during 24 months ( $r=-0.14, P=0.137)$.

\section{Change in insulin dose and BMI}

Prescribed insulin doses increased over the study period. Overall daily insulin dose increased by 4.9 units (1.7-8.0) $(P=0.003)$, daily basal dose increased by 2.4 units $(1.3-3.4)(P<0.0001)$, and daily bolus dose increased by 3.2 units $(0.8-5.7)(P=0.011)$. However, when assessed as units per kilogram bodyweight, it decreased non-significantly over 24 months (Supplementary table 5).

BMI increased with $1.8 \mathrm{~kg} / \mathrm{m}^{2}(1.4-2.1)$ during 24 months $(P<0.0001)$. BMl adjusted for age increased by $0.13 \mathrm{SDS}(0.02-0.24)(P=0.026)$. 


\section{Self-reported adverse events and complaints with isCGM}

Although users were very satisfied with the system, $64 \%$ ( $n=88 / 138)$ of participants reported 349 negative user experiences with the device.

Comments were mainly regarding the frequent sensor loss ( $n=50 / 138$ [36\%], 31\% of comments) and accuracy ( $n=52 / 138$ [38\%], 27\% of comments). Other comments were related to wearing comfort and pain ( $n=28 / 138[20 \%], 12 \%$ of comments), skin irritation or allergy $(n=23 / 138[17 \%], 10 \%$ of comments), technical issues ( $n=21 / 138$ [15\%], $9 \%$ of comments), and visibility on the upper arm ( $n=12 / 138[9 \%], 5 \%$ of comments).

\section{DISCUSSION}

This study shows that isCGM in a real-world pediatric population increases self-reported treatment satisfaction, without changing overall diabetes-related quality of life, and is well accepted by the children and their parents. With use of is CGM, less days off school for the children with T1D and less days off work for their parents could be achieved. However, there was no impact on acute hypoglycemia complications and diabetes-related hospitalizations. On the other hand, metabolic control worsened with an increase in $\mathrm{HbA1C}$ and $\mathrm{BMI}$ for the total population.

Since August 2016, isCGM is fully reimbursed in Belgium for children with T1D from 4 years of age onward. Full reimbursement was already implemented for adults with T1D one month earlier. This made it possible to study the use of isCGM in our pediatric population without the burden of financial constraints, which is often a reason to discontinue diabetes devices. ${ }^{20}$ Here, only $5 \%$ decided to stop the use of isCGM, which is lower than in other populations where reimbursement was not provided. ${ }^{14,16,21}$

Patient-reported outcome measures (PROMs) are more and more recognized as important endpoints in clinical studies evaluating new interventions in the management of diabetes. They provide us with qualitative information regarding the impact on daily life, and are powerful tools to inform patients, clinicians, and policy-makers. ${ }^{22}$ This study incorporated several PROMs, such as diabetes-specific quality of life questionnaires, satisfaction scales, and the potential to point out complaints about isCGM. When considering isCGM in an unselected population, these PROMs should be combined to allow for a complete evaluation. To start with, our population perceived their quality of life as good, with high satisfaction with life, moderate impact of diabetes on their quality of daily living, and relatively low worries about diabetes. ${ }^{23}$ This did not change when isCGM was introduced, with even higher satisfaction on the DQOLY questionnaire up to 12 months. This is in line with results from isCGM 
use among adults with T1D. ${ }^{24}$ This suggests that, when studying an unselected population of people with T1D, quality of life scores will be relatively high, which makes it rather difficult to show any improvement. Another important quality of life factor is fear of hypoglycemia, as it presents a major psychological barrier to achieving optimal glycemic control. ${ }^{25}$ Although, changes were not significantly different for HFS-behavior and HFS-worry, there was a recurring trend towards increasing behavior and decreasing worry scores. This could indicate that with isCGM, they were able to intervene earlier on upcoming lows with a decrease in fear. However, through the visualization of all glucose values, more hypoglycemic events may have come to light which previously remained undetected or unrecognized, ${ }^{26}$ prompting children and parents to take more defensive actions to prevent hypoglycemia.

As T1D is a chronic disease and life-long therapy is needed, it is important for technology to be userfriendly without debilitating effects on quality of daily living, which in term allows for high device uptake. As observed in other studies, ${ }^{27-29}$ device acceptance was high as seen by unambiguous scores on system utilization and self-reported satisfaction. They preferred isCGM over capillary glucose tests, however, more than half of participants reported problems with the device. By gathering device complaints, healthcare practitioners can inform future isCGM users to keep the frequently reported problems into mind, which in turn may result in less frustrations when problems arise. In the present study, the most frequently reported problems were due to early sensor loss and perceived low accuracy. There are several arguments for the latter. First, the delay in glucose concentration variation between the blood and the interstitial fluid causes a lag time of 5-15 minutes and is inherent to glucose sensors. ${ }^{30}$ Further, when the glucose is rapidly changing, the lag time will be more prominent. ${ }^{31}$ And last, sensor accuracy is lower during the first 24 hours after insertion ${ }^{32}$ as a consequence of tissue trauma and a compromised skin barrier, which may lead to inflammation. ${ }^{33}$ To avoid a distrust in sensor values, it remains important to explain the concept of lag time and advise people when a confirmatory capillary glucose test is warranted. Other frequently reported issues were pain and skin irritation/allergy due to the sensor or adhesive patch. Seventeen percent reported the development of skin reactions and is in line with other reported incidences in children. ${ }^{16,21}$

To the best of our knowledge, this is the first long-term study assessing changes in school and work absence after initiation of CGM in children. For the children as well as for the parents, we observed a continuing decrease in absence days from school and work, representing an important advantage on both individual and societal level. Previous studies have reported higher levels of absenteeism for children with T1D compared to their healthy peers and siblings, ${ }^{34-39}$ which is associated with poorer school results even after controlling for demographic and socioeconomic characteristics. ${ }^{37,38,40}$ Studies pointed out that lower educational achievements may subsequently impact labor market 
opportunities leading to a higher likelihood to be unemployed after school with lower income and a higher chance of early retirement. ${ }^{37,40,41}$ It should be kept in mind that these studies looked at individuals who spent their childhood in the $20^{\text {th }}$ century, thus without the availability of modern diabetes technology. Therefore, new long-term studies are needed to understand the impact of CGM on participation in society, as being able to manage diabetes in a timely manner may positively impact educational results by a reduction in cognitive deficits. Furthermore, a child spends between 8-10 hours per day at school. It is therefore crucial that school personnel provides the support the child needs to manage diabetes effectively. Diabetes management training for school personnel is part of the standard of care when a child is diagnosed with T1D in Belgium and many other Western countries. ${ }^{42}$ However, deficiencies to support diabetes self-care in the young contribute to poor glycemic control and subsequent poorer educational attainement. ${ }^{43}$ The ever-growing list of technological innovations to be used in the management of diabetes does not make it easier for school personnel to oversee diabetes self-management. ${ }^{44}$ Differences between capillary glucose values and sensor readings should be explained to school personnel to avoid wrong treatment decisions due to a poor knowledge of the device, complemented with frequent updates when new information is available. ${ }^{45}$

This single-center unselected pediatric population was well-controlled at baseline with mean HbA1c of $7.2 \%(55 \mathrm{mmol} / \mathrm{mol})$, which is better than what has been reported for other studies assessing impact of is CGM, ${ }^{14-16,28,46,47}$ for general populations followed through diabetes registries, ${ }^{48-51}$ and even for the whole Belgian pediatric population..$^{52}$ We are the first to follow a population up to 24 months after isCGM initiation. Unfortunately, after initiating isCGM, $\mathrm{HbA1c}$ increased and reached a plateau at $7.6 \%$ (60 mmol/mol) after 12 months. Studies with poorly controlled subjects observed a modest decrease in HbA1c after 2 to 3 months. ${ }^{14,28,46,47}$ Only one of these studies followed the study population for a longer period of time, here $\mathrm{HbA1c}$ was not different after 12 months of isCGM use than at baseline. ${ }^{14}$ Our results are different from the study of Bolinder et al. where adults with mean HbA1c of $6.7 \%$ (50 $\mathrm{mmol} / \mathrm{mol}$ ) were randomized to isCGM or capillary glucose tests for 6 months. They observed no change in $\mathrm{HbA} 1 \mathrm{c}$ for their well-controlled population..$^{53}$ We observed a simultaneous increase in BMI and no decrease in prescribed insulin doses. Together with a trend towards higher scores on the behavior subscale of the HFS questionnaire, this would suggest that $\mathrm{HbA1c}$ increased as a consequence of more defensive snacking to prevent hypoglycemia. Due to the easiness of measuring glucose with isCGM, lower glucose levels are noticed much faster than with capillary glucose tests. ${ }^{53}$ Additionally, isCGM also provides trend arrows upon scanning. It is our clinical experience that when a downward trend arrow is shown with normoglycemic levels, too quickly this is seen as a state that needs correction. So, earlier awareness can result in people treating hypoglycemia at a higher glucose level 
than they would have previously done without ample reduction in carbohydrate intake, thereby increasing subsequent glucose values. There is also the risk of wrong sensor readings, because isCGM sensors have been shown to have lower accuracy in the hypoglycemic range and when glucose is fluctuating. ${ }^{31,32,54}$ In addition, it has been reported that pressure-induced sensor attenuation can cause false low measurements, ${ }^{55}$ especially seen at night, and thus hyperglycemia due to unnecessary carbohydrate intake. Therefore, making treatment decisions based on isCGM values is not allowed under these circumstances ${ }^{56}$ All these factors only came to the attention of clinicians during the first year of the study. Hence, proposed diabetes treatment changes at standard diabetes consultations did not yet take these caveats into account, contributing to the increase in $\mathrm{HbA1C}$ and BMI with possibly hyperglycemia, during the first 12 months. Data is emerging about the possible negative impact of hyperglycemia on cognitive function in youth with T1D. ${ }^{57}$ Therefore, continued efforts are needed to improve education about the use of isCGM with a focus on timely and adapted treatment changes based on the sensor glucose level, trend arrows, and the understanding when confirmatory capillary glucose tests are necessary.

Even though the landscape of glucose monitoring technology changes rapidly as seen by the high turnover rate and the development of even more complex and automated systems, we believe that the results from this study are still relevant for tomorrow's diabetes management. Namely, it will be a long time before every child with T1D will be able to use complex devices like closed-loop systems, because of the high cost and lack of availability through reimbursement programs. In this regard, isCGM (specifically FreeStyle Libre) will remain an important player, due to its cheaper price, ease of use, and higher penetrance in the CGM market. When considering a high glucose test frequency, isCGM is even more economical than capillary glucose tests. ${ }^{58}$ At the end of 2018 , the secondgeneration FreeStyle Libre was selectively launched in Europe. It adds optional real-time alarms for hypo- and hyperglycemia (only an indication if glucose is high or low), is said to be more accurate than the previous generation, and the allergen isobornyl acrylate is removed from the adhesive patch. ${ }^{59,60}$ However, in 2020 still the majority of people use the first-generation FreeStyle Libre. It remains to be evaluated what the added benefit of these optional alarms will be on an isCGM system. Nonetheless, education will continue to be an important aspect to achieve optimal diabetes control while using glucose monitoring technology.

Our study has limitations, like the fact that the we did not have a control group and that severe hypoglycemic events prior to initiation could only be recorded by recall. However, all hospitalizations for hypoglycemia and ketoacidosis were validated using the hospital records of the participants. Further, we only report on outcomes of one pediatric center, so it is not known if this team or its patient population is representative of other centers across the country. Next, we only assessed quality 
of life changes among the children, but it is also important to question the parents about the impact of isCGM on their lives. The most important limitation lies in the fact that we were not able to assess changes in time spent in different glycemic ranges, which would also be of interest to look for associations between time in ranges and the decrease in school absence days.

Despite these limitations, of which some are inherent to an observational study, we provide valuable data on the real-life unrestricted use of isCGM in a well-controlled pediatric population with T1D. It is namely associated with high treatment satisfaction and less days of absence from school. However, metabolic control was worse after 24 months with also an increase in BMI. Thus, regular education on how to cope with trend arrows, lag time, and sensor errors will be imperative to teach children, parents, and school personnel to apply effective diabetes management.

\section{REFERENCES}

1. Gerstl E-M, RabI W, Rosenbauer J, et al. Metabolic control as reflected by HbA1c in children, adolescents and young adults with type-1 diabetes mellitus: combined longitudinal analysis including 27,035 patients from 207 centers in Germany and Austria during the last decade. Eur J Pediatr. 2008;167(4):447-453.

2. Clements MA, Foster NC, Maahs DM, et al. Hemoglobin A1c (HbA1c) changes over time among adolescent and young adult participants in the T1D exchange clinic registry. Pediatr Diabetes. 2016;17(5):327-336.

3. Diabetes Control and Complications Trial Research Group. Effect of intensive diabetes treatment on the development and progression of long-term complications in adolescents with insulin-dependent diabetes mellitus: Diabetes Control and Complications Trial. J Pediatr. 1994;125(2):177-188.

4. Cooper MN, Lin A, Alvares GA, de Klerk NH, Jones TW, Davis EA. Psychiatric disorders during early adulthood in those with childhood onset type 1 diabetes: Rates and clinical risk factors from population-based follow-up. Pediatr Diabetes. 2017;18(7):599-606.

5. Hassan K, Loar R, Anderson BJ, Heptulla RA. The role of socioeconomic status, depression, quality of life, and glycemic control in type 1 diabetes mellitus. J Pediatr. 2006;149(4):526531.

6. Danne T, Nimri R, Battelino T, et al. International Consensus on Use of Continuous Glucose Monitoring. Diabetes Care. 2017;40(12):1631-1640. 
7. Charleer S, Mathieu C, Nobels F, et al. Effect of Continuous Glucose Monitoring on Glycemic Control, Acute Admissions, and Quality of Life: A Real-World Study. J Clin Endocrinol Metab. 2018;103(3):1224-1232.

8. Tamborlane W V, Beck RW, Bode BW, et al. Continuous glucose monitoring and intensive treatment of type 1 diabetes. N Engl J Med. 2008;359(14):1464-1476.

9. Polonsky WH, Hessler D, Ruedy KJ, Beck RW. The Impact of Continuous Glucose Monitoring on Markers of Quality of Life in Adults With Type 1 Diabetes: Further Findings From the DIAMOND Randomized Clinical Trial. Diabetes Care. 2017;40(6):736-741.

10. van Beers CAJ, DeVries JH, Kleijer SJ, et al. Continuous glucose monitoring for patients with type 1 diabetes and impaired awareness of hypoglycaemia (IN CONTROL): a randomised, open-label, crossover trial. Lancet Diabetes Endocrinol. 2016;4(11):893-902.

11. Battelino T, Phillip M, Bratina N, Nimri R, Oskarsson P, Bolinder J. Effect of continuous glucose monitoring on hypoglycemia in type 1 diabetes. Diabetes Care. 2011;34(4):795-800.

12. Chase HP, Beck RW, Xing D, et al. Continuous glucose monitoring in youth with type 1 diabetes: 12-month follow-up of the Juvenile Diabetes Research Foundation continuous glucose monitoring randomized trial. Diabetes Technol Ther. 2010;12(7):507-515.

13. Heinemann L, Freckmann G. CGM Versus FGM; or, Continuous Glucose Monitoring Is Not Flash Glucose Monitoring. J Diabetes Sci Technol. 2015;9(5):947-950.

14. Pintus D, Ng SM. Freestyle libre flash glucose monitoring improves patient quality of life measures in children with Type 1 diabetes mellitus (T1DM) with appropriate provision of education and support by healthcare professionals. Diabetes Metab Syndr. 2019;13(5):29232926.

15. Messaaoui A, Tenoutasse S, Crenier L. Flash Glucose Monitoring Accepted in Daily Life of Children and Adolescents with Type 1 Diabetes and Reduction of Severe Hypoglycemia in Real-Life Use. Diabetes Technol Ther. 2019;21(6):329-335.

16. Landau Z, Abiri S, Gruber N, et al. Use of flash glucose-sensing technology (FreeStyle Libre) in youth with type 1 diabetes: AWeSoMe study group real-life observational experience. Acta Diabetol. 2018;55(12):1303-1310.

17. Cole TJ, Freeman J V, Preece MA. Body mass index reference curves for the UK, 1990. Arch Dis Child. 1995;73(1):25-29. 
18. Ingersoll GM, Marrero DG. A modified quality-of-life measure for youths: psychometric properties. Diabetes Educ. 1991;17(2):114-118.

19. Green LB, Wysocki T, Reineck BM. Fear of hypoglycemia in children and adolescents with diabetes. J Pediatr Psychol. 1990;15(5):633-641.

20. Tanenbaum ML, Hanes SJ, Miller KM, Naranjo D, Bensen R, Hood KK. Diabetes Device Use in Adults With Type 1 Diabetes: Barriers to Uptake and Potential Intervention Targets. Diabetes Care. 2017;40(2):181-187.

21. Vergier J, Samper M, Dalla-Vale F, et al. Evaluation of flash glucose monitoring after long-term use: A pediatric survey. Prim Care Diabetes. 2019;13(1):63-70.

22. Deshpande PR, Rajan S, Sudeepthi BL, Abdul Nazir CP. Patient-reported outcomes: A new era in clinical research. Perspect Clin Res. 2011;2(4):137-144.

23. Grey M, Boland EA, Yu C, Sullivan-Bolyai S, Tamborlane W V. Personal and family factors associated with quality of life in adolescents with diabetes. Diabetes Care. 1998;21(6):909914.

24. Charleer S, De Block C, Van Huffel L, et al. Quality of Life and Glucose Control After 1 Year of Nationwide Reimbursement of Intermittently Scanned Continuous Glucose Monitoring in Adults Living With Type 1 Diabetes (FUTURE): A Prospective Observational Real-World Cohort Study. Diabetes Care. 2020;43(2):389-397.

25. Cryer PE. Hypoglycemia: still the limiting factor in the glycemic management of diabetes. Endocr Pract. 2008;14(6):750-756.

26. Gonder-Frederick L, Zrebiec J, Bauchowitz A, et al. Detection of hypoglycemia by children with type 1 diabetes 6 to 11 years of age and their parents: a field study. Pediatrics. 2008;121(3):e489-95.

27. Al Hayek AA, Robert AA, Al Dawish MA. Acceptability of the FreeStyle Libre Flash Glucose Monitoring System: The Experience of Young Patients With Type 1 Diabetes. Clin Med Insights Endocrinol Diabetes. 2020;13:1179551420910122.

28. Campbell FM, Murphy NP, Stewart C, Biester T, Kordonouri O. Outcomes of using flash glucose monitoring technology by children and young people with type 1 diabetes in a single arm study. Pediatr Diabetes. 2018;19(7):1294-1301.

29. Al Hayek AA, Al Dawish MA. The Potential Impact of the FreeStyle Libre Flash Glucose 
Monitoring System on Mental Well-Being and Treatment Satisfaction in Patients with Type 1 Diabetes: A Prospective Study. Diabetes Ther. 2019;10(4):1239-1278.

30. Sinha M, McKeon KM, Parker S, et al. A Comparison of Time Delay in Three Continuous Glucose Monitors for Adolescents and Adults. J Diabetes Sci Technol. 2017;11(6):1132-1137.

31. Szadkowska A, Gawrecki A, Michalak A, Zozulinska-Ziolkiewicz D, Fendler W, Mlynarski W. Flash Glucose Measurements in Children with Type 1 Diabetes in Real-Life Settings: To Trust or Not to Trust? Diabetes Technol Ther. 2018;20(1):17-24.

32. Charleer S, Mathieu C, Nobels F, Gillard P. Accuracy and precision of flash glucose monitoring sensors inserted into the abdomen and upper thigh compared with the upper arm. Diabetes, Obes Metab. 2018;20(6):1503-1507.

33. Koschinsky T, Heinemann L. Sensors for glucose monitoring: technical and clinical aspects. Diabetes Metab Res Rev. 2001;17(2):113-123.

34. Vetiska J, Glaab L, Perlman K, Daneman D. School attendance of children with type 1 diabetes. Diabetes Care. 2000;23(11):1706-1707.

35. Glaab LA, Brown R, Daneman D. School attendance in children with Type 1 diabetes. Diabet Med. 2005;22(4):421-426.

36. Parent KB, Wodrich DL, Hasan KS. Type 1 diabetes mellitus and school: a comparison of patients and healthy siblings. Pediatr Diabetes. 2009;10(8):554-562.

37. Fleming M, Fitton CA, Steiner MFC, et al. Educational and Health Outcomes of Children Treated for Type 1 Diabetes: Scotland-Wide Record Linkage Study of 766,047 Children. Diabetes Care. 2019;42(9):1700-1707.

38. McCarthy AM, Lindgren S, Mengeling MA, Tsalikian E, Engvall J. Factors associated with academic achievement in children with type 1 diabetes. Diabetes Care. 2003;26(1):112-117.

39. Yu SL, Kail R, Hagen JW, Wolters CA. Academic and Social Experiences of Children With InsulinDependent Diabetes Mellitus. Child Heal Care. 2000;29(3):189-207.

40. Persson S, Dahlquist G, Gerdtham U-G, Steen Carlsson K. Impact of childhood-onset type 1 diabetes on schooling: a population-based register study. Diabetologia. 2013;56(6):12541262.

41. Persson S, Dahlquist G, Gerdtham U-G, Steen Carlsson K. Why childhood-onset type 1 diabetes impacts labour market outcomes: a mediation analysis. Diabetologia. 
2018;61(2):342-353.

42. Pansier B, Schulz PJ. School-based diabetes interventions and their outcomes: a systematic literature review. J Public health Res. 2015;4(1):467.

43. Särnblad S, Berg L, Detlofsson I, Jonsson A, Forsander G. Diabetes management in Swedish schools: a national survey of attitudes of parents, children, and diabetes teams. Pediatr Diabetes. 2014;15(8):550-556.

44. March CA, Nanni M, Kazmerski TM, Siminerio LM, Miller E, Libman IM. Modern diabetes devices in the school setting: Perspectives from school nurses. Pediatr Diabetes. 2020;21(5):832-840.

45. Bratina N, Forsander G, Annan F, et al. ISPAD Clinical Practice Consensus Guidelines 2018: Management and support of children and adolescents with type 1 diabetes in school. Pediatr Diabetes. 2018;19 Suppl 2:287-301.

46. Al Hayek AA, Robert AA, Al Dawish MA. Effectiveness of the Freestyle Libre Flash Glucose Monitoring System on Diabetes Distress Among Individuals with Type 1 Diabetes: A Prospective Study. Diabetes Ther. 2020;11(4):927-937.

47. Al Hayek AA, Robert AA, Al Dawish MA. Evaluation of FreeStyle Libre Flash Glucose Monitoring System on Glycemic Control, Health-Related Quality of Life, and Fear of Hypoglycemia in Patients with Type 1 Diabetes. Clin Med Insights Endocrinol Diabetes. 2017;10:1179551417746957.

48. Foster NC, Beck RW, Miller KM, et al. State of Type 1 Diabetes Management and Outcomes from the T1D Exchange in 2016-2018. Diabetes Technol Ther. 2019;21(2):66-72.

49. Bohn B, Karges B, Vogel C, et al. 20 Years of Pediatric Benchmarking in Germany and Austria: Age-Dependent Analysis of Longitudinal Follow-Up in 63,967 Children and Adolescents with Type 1 Diabetes. PLoS One. 2016;11(8):e0160971.

50. Peterson A, Hanberger L, Akesson K, Bojestig M, Andersson Gare B, Samuelsson U. Improved results in paediatric diabetes care using a quality registry in an improvement collaborative: a case study in Sweden. PLoS One. 2014;9(5):e97875.

51. Royal College of Paediatrics and Child Health. National Paediatric Diabetes Audit core report: Care Processes and Outcomes 2018/19. Published 2020. Accessed May 12, 2020. https://www.rcpch.ac.uk/sites/default/files/2020-03/final_npda_core_report_2018-2019.pdf 
52. Chao S, Doggen K. Initiatief voor kwaliteitsbevordering en epidemiologie bij kinderen en adolescenten met diabetes (IKEKAD) - Resultaten 2017. Published 2019. Accessed May 15, 2020. https://www.sciensano.be/nl/biblio/initiatief-voor-kwaliteitsbevordering-enepidemiologie-bij-kinderen-en-adolescenten-met-diabetes-2

53. Bolinder J, Antuna R, Geelhoed-Duijvestijn P, Kroger J, Weitgasser R. Novel glucose-sensing technology and hypoglycaemia in type 1 diabetes: a multicentre, non-masked, randomised controlled trial. Lancet. 2016;388(10057):2254-2263.

54. Hansen EA, Klee P, Dirlewanger M, et al. Accuracy, satisfaction and usability of a flash glucose monitoring system among children and adolescents with type 1 diabetes attending a summer camp. Pediatr Diabetes. 2018;19(7):1276-1284.

55. Baysal N, Cameron F, Buckingham BA, et al. A novel method to detect pressure-induced sensor attenuations (PISA) in an artificial pancreas. J Diabetes Sci Technol. 2014;8(6):10911096.

56. DiMeglio LA, Acerini CL, Codner E, et al. ISPAD Clinical Practice Consensus Guidelines 2018: Glycemic control targets and glucose monitoring for children, adolescents, and young adults with diabetes. Pediatr Diabetes. 2018;19 Suppl 2:105-114.

57. Kirchhoff BA, Jundt DK, Doty T, Hershey T. A longitudinal investigation of cognitive function in children and adolescents with type 1 diabetes mellitus. Pediatr Diabetes. 2017;18(6):443-449.

58. Hellmund R, Weitgasser R, Blissett D. Cost calculation for a flash glucose monitoring system for UK adults with type 1 diabetes mellitus receiving intensive insulin treatment. Diabetes Res Clin Pract. 2018;138:193-200.

59. Abbott. Abbott's FreeStyle ${ }^{\circledR}$ Libre 2 iCGM Cleared in U.S. for Adults and Children with Diabetes, Achieving Highest Level of Accuracy and Performance Standards. Published June 15, 2020. Accessed July 1, 2020. https://abbott.mediaroom.com/2020-06-15-Abbotts-FreeStyleR-Libre-2-iCGM-Cleared-in-U-S-for-Adults-and-Children-with-Diabetes-Achieving-HighestLevel-of-Accuracy-and-Performance-Standards

60. Oppel E, Kamann S, Heinemann L, Klein A, Reichl F-X, Högg C. Freestyle libre 2: The new isobornyl acrylate free generation. Contact Dermatitis. Published online June 15, 2020:cod.13638. 


\section{TABLES}

Table 1. Baseline characteristics

\begin{tabular}{|c|c|}
\hline Total number of participants & 138 \\
\hline \multicolumn{2}{|l|}{ Gender } \\
\hline Girls & 75 (54.3\%) \\
\hline Boys & $63(45.7 \%)$ \\
\hline \multicolumn{2}{|l|}{ Age (years) } \\
\hline Mean & $12.9(3.1)$ \\
\hline 4 to 6 & $5(3.6 \%)$ \\
\hline 7 to 12 & $49(35.5 \%)$ \\
\hline 13 to 18 & $84(60.9 \%)$ \\
\hline Height (m), (inches) & $1.58(0.2), 62.2(7.1)$ \\
\hline Weight (kg), (lbs) & 51.0 (16.7), 112.4 (36.8) \\
\hline BMI $\left(\mathrm{kg} / \mathrm{m}^{2}\right)$ & $19.8(3.5)$ \\
\hline \multicolumn{2}{|l|}{ Education level parents } \\
\hline Higher $^{+}$ & $76(55.1 \%)$ \\
\hline No higher & $25(18.1 \%)$ \\
\hline Unknown & $37(26.8 \%)$ \\
\hline Years since type 1 diabetes diagnosis & $5.4(3.9)$ \\
\hline Baseline $\mathrm{HbA} 1 \mathrm{c}(\%),(\mathrm{mmol} / \mathrm{mol})$ & $7.2(1.1), 55$ (11) \\
\hline \multicolumn{2}{|l|}{ Insulin administration method } \\
\hline Insulin pump therapy & $27(19.6 \%)$ \\
\hline Multiple daily insulin injections & $111(80.4 \%)$ \\
\hline \multicolumn{2}{|l|}{ Insulin, total daily dose (units/kg) } \\
\hline Overall & $0.91(0.32)$ \\
\hline Basal & $0.32(0.14)$ \\
\hline Bolus & $0.58(0.22)$ \\
\hline \multicolumn{2}{|l|}{ Insulin, total daily dose (units) } \\
\hline Overall & $48.2(26.3)$ \\
\hline Basal & $17.4(10.5)$ \\
\hline Bolus & $30.5(17.1)$ \\
\hline Impaired awareness of hypoglycemia & $12(8.7 \%)$ \\
\hline
\end{tabular}

Data are $\mathrm{n}(\%)$ or mean (SD). ${ }^{\dagger}$ At least one of the two parents graduated from university or college. 
Table 2. Quality of life scores before and after initiation of intermittently scanned continuous glucose monitoring

\begin{tabular}{lllll}
\hline & baseline & 6 months & 12 months & 24 months \\
\hline DQOLY & & & & \\
Satisfaction & $68.8(67.4-70.3)$ & $71.9(70.3-73.4)^{* * *}$ & $71.2(69.8-72.7)^{* * *}$ & $70.2(68.8-71.5)$ \\
Impact & $52.1(50.1-54.0)$ & $50.5(48.8-52.1)^{*}$ & $50.8(49.0-52.7)$ & $50.3(48.4-52.1)$ \\
$\quad$ Worry & $18.8(17.6-20.0)$ & $18.4(17.1-19.7)$ & $18.6(17.4-19.8)$ & $18.1(17.0-19.2)$ \\
HFS for children & & & & \\
Behavior & $16.1(15.1-17.2)$ & $16.4(15.3-17.4)$ & $16.4(15.4-17.4)$ & $17.0(15.9-18.2)$ \\
Worry & $14.7(13.2-16.1)$ & $14.7(13.1-16.3)$ & $13.5(12.2-14.8)$ & $14.1(12.8-15.4)$ \\
\hline
\end{tabular}

Data are least-squares mean (95\% confidence interval). DQOLY=Diabetes Quality of Life for Youth, HFS=Hypoglycemia Fear Survey. ${ }^{*} P<0.05,{ }^{* *} P<0.01,{ }^{* * *} P<0.001$ for the comparison with the baseline score.

DQOLY satisfaction score ranges from 17 to 85; high scores indicate much more satisfied. DQOLY impact score ranges from 23 to 115; high scores indicate high impact of diabetes on life. DQOLY worry score ranges from 13 to 65; high scores indicate many worries about diabetes. HFS behavior score ranges from 0 to 40; high scores indicate frequent hypoglycemia avoidant behaviors. HFS worry score ranges from 0 to 60; high scores indicate many worries related to hypoglycemia. 
Table 3. Diabetes-related acute complications and school absenteeism before and after initiation of intermittently scanned continuous glucose monitoring

baseline $\quad 6$ months 12 months 24 months

\begin{tabular}{|c|c|c|c|c|}
\hline \multicolumn{5}{|l|}{ People with } \\
\hline Hospitalizations due to hypoglycemia and/or ketoacidosis ${ }^{\ddagger \ddagger}$ & $9(6.5 \%)$ & .. & $3(2.2 \%)$ & $8(6.6 \%)$ \\
\hline Hospitalizations due to hypoglycemia ${ }^{\ddagger}$ & $7(5.1 \%)$ & .. & $2(1.5 \%)$ & $1(0.8 \%)$ \\
\hline Hospitalizations due to ketoacidosis $^{\dagger \neq}$ & $2(1.4 \%)$ & .. & $1(0.7 \%)$ & $7(5.7 \%)$ \\
\hline Help from third parties due to hypoglycemia ${ }^{\S}$ & $19(13.8 \%)$ & $13(9.5 \%)$ & $12(9.0 \%)$ & $16(13.1 \%)$ \\
\hline Hypoglycemic comas ${ }^{\S}$ & $3(2.2 \%)$ & $0(0 \%)$ & $1(0.7 \%)$ & $1(0.8 \%)$ \\
\hline School absenteeism ${ }^{\S}$ & $19(13.8 \%)$ & $13(9.5 \%)$ & $9(6.7 \%)$ & $6(4.9 \%)$ \\
\hline Work absenteeism by parents ${ }^{\S}$ & $27(19.6 \%)$ & $25(18.2 \%)$ & $15(11.2 \%)$ & $10(8.2 \%)$ \\
\hline \multicolumn{5}{|l|}{ Number per 100 patient-years of } \\
\hline Help from third parties due to hypoglycemia ${ }^{\ddagger}$ & 65.2 & .. & 37.3 & 59.0 \\
\hline Hypoglycemic comas ${ }^{\ddagger}$ & 5.8 & .. & 0.7 & 1.6 \\
\hline \multicolumn{5}{|l|}{ Days per 100 patient-years of } \\
\hline Hospitalizations due to hypoglycemia and/or ketoacidosis ${ }^{\dagger \neq}$ & 18.8 & .. & $7.1^{*}$ & 26.4 \\
\hline Hospitalizations due to hypoglycemia $^{\ddagger}$ & 2.9 & .. & $0.4^{*}$ & 5.7 \\
\hline Hospitalizations due to ketoacidosis $^{\dagger \neq}$ & 15.9 & .. & 6.7 & 20.7 \\
\hline School absenteeism ${ }^{\ddagger}$ & 227.5 & .. & 65.2 & $13.1^{*}$ \\
\hline Work absenteeism by parents ${ }^{\ddagger}$ & 149.3 & .. & 87.3 & $18.0^{*}$ \\
\hline
\end{tabular}




\section{FIGURE LEGENDS}

Figure 1. HbA1c from baseline to $\mathbf{2 4}$ months after initiation of intermittently scanned continuous glucose monitoring for the total population, groups based on baseline HbA1c, age, and scan frequency

Data points represent least-squares mean (95\% confidence interval) of HbA1c measurements in percent (upper number) and $\mathrm{mmol} / \mathrm{mol}$ (lower number) per time point for (A) the total population, (B) as a function of baseline $\mathrm{HbA1C}$, (C) as a function of age, and (D) as a function mean scan frequency over 24 months.

${ }^{* * *} P<0.001,{ }^{* *} P<0.01$, and ${ }^{*} P<0.05$ for the comparisons versus baseline $\mathrm{HbA1C}$.

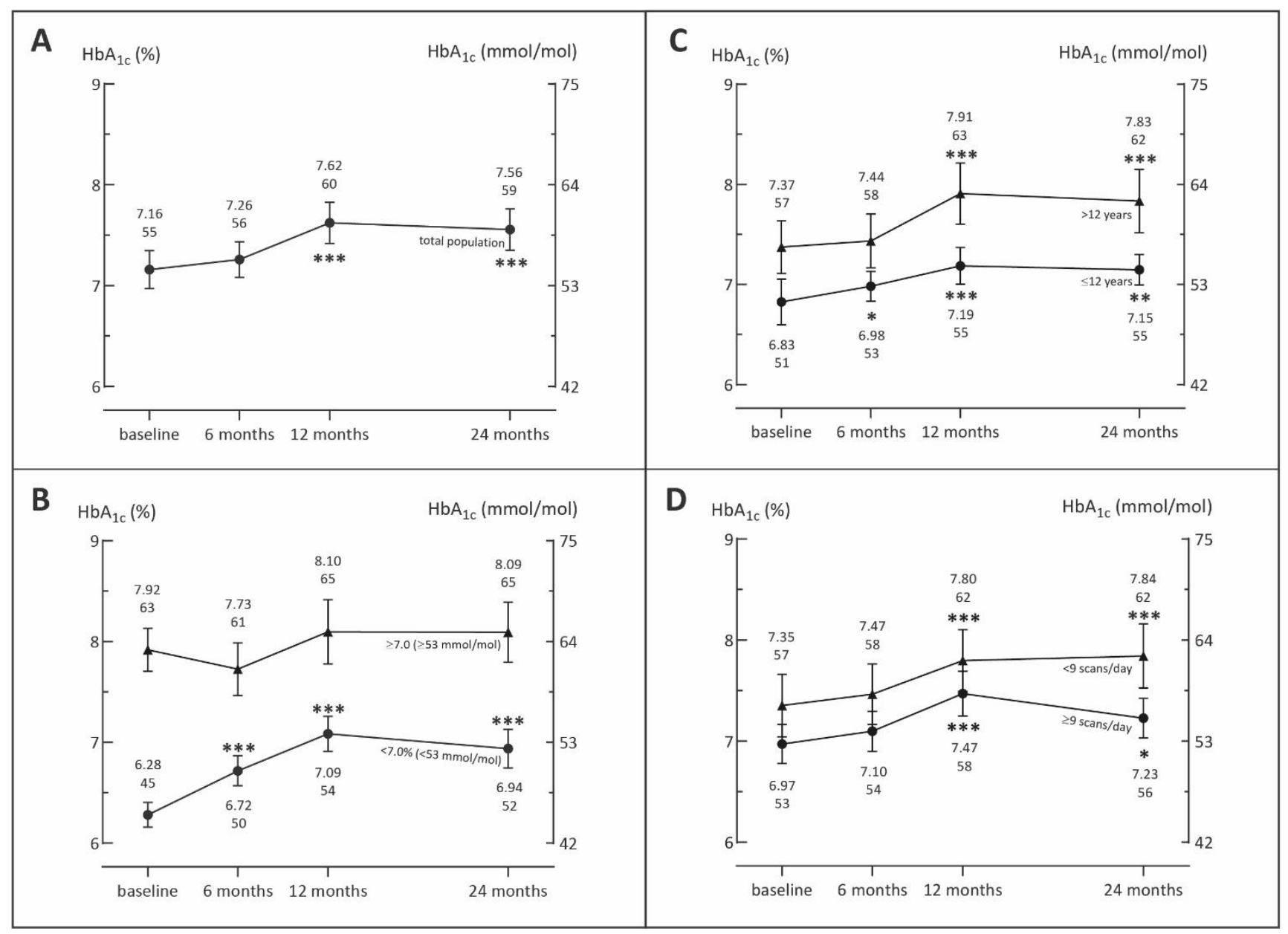

